Note

\title{
Enzymatic Production of Glucosylxylose Using a Cellobiose Phosphorylase-Yeast Combined System
}

\author{
(Received Date: August 3, 2010; Accepted Date: October 14, 2010) \\ (J-STAGE Advance Published Date: November 29, 2010) \\ Akio Kumagai, ${ }^{1}$ Sawaki Tada, ${ }^{2}$ Kouichi Nozaki, ${ }^{1}$ Masahiro Mizuno, ${ }^{1}$ \\ Takahisa Kanda, ${ }^{1}$ Satoshi Suzuki, ${ }^{2}$ Kenichi Kusumoto, ${ }^{2}$ Takashi Sasaki, ${ }^{2}$ \\ Yutaka Kashiwagi ${ }^{2,3}$ and Yoshihiko Amano*,1 \\ ${ }^{1}$ Department of Chemistry and Material Engineering, Faculty of Engineering, Shinshu University \\ (4-17-1 Wakasato, Nagano 380-8553, Japan) \\ ${ }^{2}$ National Food Research Institute \\ (2-1-12 Kannondai, Tsukuba 305-8642, Japan) \\ ${ }^{3}$ Department of Fermentation Science, Faculty of Applied Biosciences, Tokyo University of Agriculture \\ (1-1-1 Sakuragaoka, Setagaya, Tokyo 156-8502, Japan)
}

\begin{abstract}
Cellobiose phosphorylase (EC 2.4.1.20, CBPase) is an enzyme that catalyzes the reversible phosphorolysis of cellobiose into $\alpha$-D-glucose 1-phosphate (G-1-P) and D-glucose. As the acceptor specificity of the reverse reaction is broad, CBPase can synthesize hetero $\beta$-disaccharides from G-1-P and monosaccharides as acceptors. Here, in order to develop an efficient system for producing a rare $\beta$-disaccharide like 4-O- $\beta$-D-glucopyranosyl-D-xylopyranose (GX) using CBPase, two attempts were examined. Firstly, the CBPase gene from Cellvibrio gilvus was heterologously expressed as an intracellular enzyme using Aspergillus oryzae. The recombinant CBPase was enclosed in the mycelia of the host cell by cold acetone treatment and prepared as a mycelial dry powder. Secondly, to facilitate the synthesis of GX by removing glucose from the reaction mixture, a commercial dry yeast was added to the reaction mixture. The powdered CBPase-yeast combined system produced an approximately 3.5 times higher yield of GX from cellobiose than the reaction without yeast.
\end{abstract}

Key words: hetero-oligosaccharide, glucosylxylose, cellobiose phosphorylase, acetone-treatment mycelia

The enzymatic synthesis of hetero disaccharides or oligosaccharides by various phosphorylases is an important technique for producing new oligosaccharides. Cellobiose phosphorylase (EC 2.4.1.20, CBPase) is an enzyme that catalyzes the reversible phosphorolysis of cellobiose into glucose 1-phosphate (G-1-P) and glucose. ${ }^{1)}$ It was found that CBPase exhibits broad accepter specificity in the reverse reaction, and several hetero $\beta$-disaccharides such as $4-O-\beta-\mathrm{D}$ glucopyranosyl-D-xylopyranose (GX) have been synthesized using this reaction. ${ }^{2)}$

Recently, techniques for separating cellulosic biomass into its constituent components using hydrothermal water and enzymatic treatments have been developed. ${ }^{3)}$ After hydrothermal water treatment of cellulosic biomass, xylose and xylooligosaccharides derived from hemicellulose are contained in the soluble fraction, whereas lignocellulose remains as a residual fraction, and then these fractions are subsequently degraded by xylanase and cellulases such as endoglucanase and cellobiohydrolase, respectively. These processes allow the preparation of large amounts of xylose and cellobiose, which can be used as substrates for the synthesis of GX from cellulosic biomass by CBPase. In this study, we attempted to develop an efficient method for pro-

*Corresponding author (Tel. +81-26-269-5394, Fax. +81-26-269-5394, E-mail: yoamano@shinshu-u.ac.jp) ducing GX using CBPase.

The CBPase used in this study was from Cellvibrio gilvus, and its enzymatic properties have been well characterized. ${ }^{4)}$ This enzyme is produced as an intracellular enzyme, but its production level in C. gilvus is extremely low. Therefore, a recombinant CBPase was expressed in Aspergillus oryzae, which has the ability to express a large amount of proteins. ${ }^{5-7)}$ The construction of the expression plasmid vector was performed using the Gateway ${ }^{\mathrm{TM}}$ system (Invitrogen Corporation, Madison, USA) according to the method of Mabashi et $a l .{ }^{8)}$ The resultant plasmid contained 2,469 bp of the CBPase gene of $C$. gilvus, which was regulated by the Taka-amylase A gene $(A m y B)$ promoter, ${ }^{9)}$ and a pyrithiamine resistance gene, which was used as a selection marker. ${ }^{10)}$ This expression vector was introduced into $A$. oryzae RIB40 by the protoplast-PEG method, ${ }^{11)}$ and the resultant transformants expressed a recombinant CBPase as an intracellular enzyme in their cytoplasm. Although we also attempted to express CBPase as an extracellular protein, its expression level was very low (data not shown).

To efficiently use recombinant CBPase from the cytoplasm of $A$. oryzae, the collected mycelia were treated with cold acetone according to the method of Kitaoka et al. ${ }^{12)}$ The cell membrane was then removed by acetone-treatment without disrupting the cell wall, resulting in the preparation of a dry powder enclosing CBPase in acetone-treated myce- 
lia. After cultivation in YPS liquid medium at $30^{\circ} \mathrm{C}$ for $48 \mathrm{~h}$, the mycelia were harvested on filter paper by suction filtration. Then, the mycelia were suspended in a 10 -fold volume of dry ice-cold acetone $\left(-76^{\circ} \mathrm{C}\right)$ and stirred for $1 \mathrm{~h}$. After stirring, the mycelia were collected on a glass filter and washed twice with dry ice-cold acetone. Next, the mycelia were suspended in a double volume of ice-cold ethanol $\left(4^{\circ} \mathrm{C}\right)$ and stirred for $30 \mathrm{~min}$. The acetone-treated mycelia were finally obtained as a dry powder.

To confirm the enzymatic activity of the acetone-treated mycelia, their activity was assayed by measuring the amount of G-1-P formed from cellobiose as follows: $5 \mathrm{mg}$ of the acetone-treated mycelia were suspended in $1 \mathrm{~mL}$ of substrate solution containing $5 \mathrm{mM}$ cellobiose, $33 \mathrm{~mm}$ sodium phosphate, and $50 \mathrm{~mm}$ Tris-HCl buffer $(\mathrm{pH} 7.5) .{ }^{4)}$ After incubation at $37^{\circ} \mathrm{C}$ for $10 \mathrm{~min}$, the reaction mixture was heated at $95^{\circ} \mathrm{C}$ for $3 \mathrm{~min}$ to inactivate the enzyme, and the supernatant of the reaction mixture was collected by centrifugation at $4^{\circ} \mathrm{C}$ and 15,000 rpm for $5 \mathrm{~min}$. The concentration of G-1-P in the supernatant was analyzed using a phosphoglucomutase and G-6-P dehydrogenase system. ${ }^{13)}$ One $\mathrm{mL}$ of the supernatant and enzyme solution, which contained $0.2 \mathrm{U} / \mathrm{mL}$ phosphoglucomutase (F. Hoffmann-La Roche Ltd., Basel, Switzerland), $0.175 \mathrm{U} / \mathrm{mL}$ glucose 6-phosphate dehydrogenase (F. Hoffmann-La Roche Ltd.), $5 \mathrm{mM} \mathrm{MgCl}_{2}$, and $80 \mathrm{mM}$ $\mathrm{NADH}$ in $50 \mathrm{~mm}$ Tris-HCl buffer ( $\mathrm{pH} 7.5)$, were mixed and incubated at $37^{\circ} \mathrm{C}$ for $10 \mathrm{~min}$. After incubation, the absorbance of NADP ${ }^{+}$at $340 \mathrm{~nm}$ was measured. One unit of CBPase activity was defined as the amount of the enzyme that produced $1 \mu \mathrm{mol}$ G-1-P per min under the above conditions. As a result, $6.04 \mathrm{~g}$ of the acetone-treated mycelia were gained from $1 \mathrm{~L}$ of culture and contained 16.7 $\mathrm{U}$ of CBPase per $1 \mathrm{~g}$ of the acetone-treated mycelia.

The enzymatic activity of the CBPase powder was comparable to that of a crude extract prepared from the homogenate of $A$. oryzae CBPase ${ }^{+}$transformants (Fig. 1(a)). To confirm the possibility of the acetone-treated mycelia as an immobilized enzyme, they were subjected to repeated reactions. As a result, the activity of the acetone-treated mycelia decreased by $80 \%$ after the first reaction (Fig. 1(b)). We assumed that a large proportion of the CBPase enclosed in the cell had diffused into the solution via the cell wall. Although the CBPase powder is unlikely to be used as an immobilized enzyme, this method should have an advantage in enzyme storage.

When cellobiose as a substrate and xylose as an acceptor are mixed and incubated with CBPase, G-1-P is produced by the phosphorolysis of cellobiose and subsequently reacts with xylose to form $\mathrm{GX}$ via the reverse reaction of CBPase. It is reported that the acceptor specificity of CBPase for the reverse reaction is broad, although it shows 40 times higher affinity for glucose than xylose. ${ }^{2)}$ In order to utilize the reverse reaction effectively, it was necessary to remove the glucose produced by the phosphorolysis of cellobiose from the reaction mixture. In this study, a commercial dry yeast was added to the reaction mixture to consume the glucose produced by phosphorolysis.

GX production was carried out using the following procedures, and the products of these enzymatic reactions were analyzed by thin layer chromatography (TLC) and high performance liquid chromatography (HPLC). Since the purified

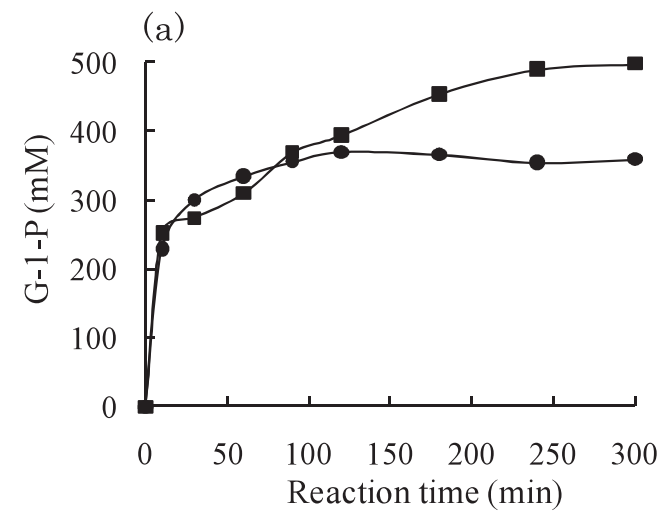

(b)

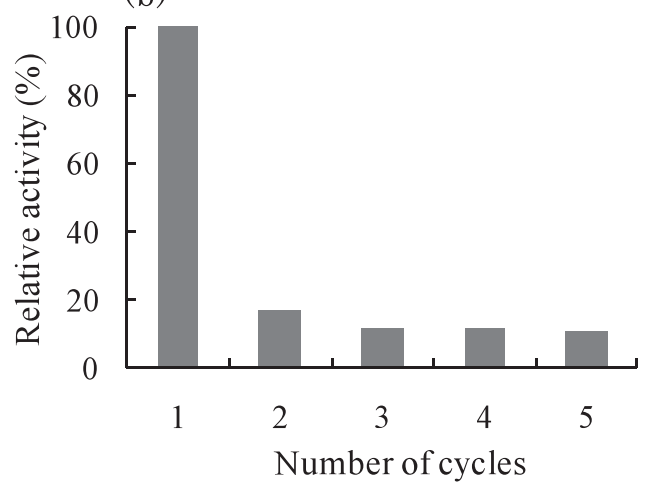

Fig. 1. Analysis of the CBPase activity of the acetone-treated mycelia.

CBPase activity was measured by determining the amount of G-1-P produced by the enzyme reaction. (a) Comparison of CBPase activity between the acetone-treated mycelia $(\square)$ and crude extract solution (O). These reactions were performed using $5 \mathrm{mg}$ of the acetone-treated mycelia (16.7 U/g of mycelia) and about $53 \mu \mathrm{L}$ of crude extract solution $(1.57 \mathrm{U} / \mathrm{mL})$. (b) Activity remaining in the acetone-treated mycelia after they had been reused several times. The acetone-treated mycelia after reaction were recovered by centrifugation at $15,000 \mathrm{rpm}$ for 10 $\min$ at $4^{\circ} \mathrm{C}$, and then the recovered mycelia were resuspended in a reaction mixture for the next reaction.

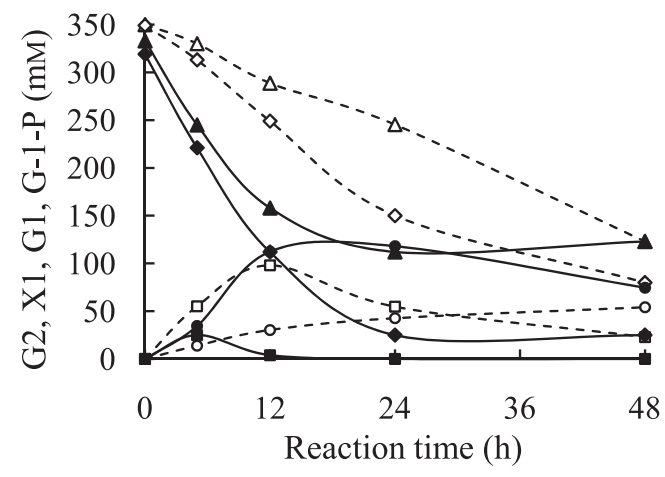

Fig. 2. Effect of the addition of dry yeast on GX production.

Quantitative determination of saccharides in the reaction mixture. Analysis was carried out with $72 \%$ acetonitrile as the solvent at $30^{\circ} \mathrm{C}$ and a flow rate of $0.5 \mathrm{~mL} / \mathrm{min}$ using an HPLC system (JASCO Corporation, Tokyo, Japan) equipped with a Shodex Asahipak NH2P-4E column (Shodex ${ }^{\circledR}$, SHOWA DENKO K.K., Tokyo, Japan) and an RI-810 detector (JASCO Corporation). The dashed and solid lines indicate the reactions without and with dry yeast, respectively. $\triangle \boldsymbol{\Lambda}$, xylose; $\diamond$ cellobiose; $\bigcirc$, GX; $\square \square$, glucose. 
(a)

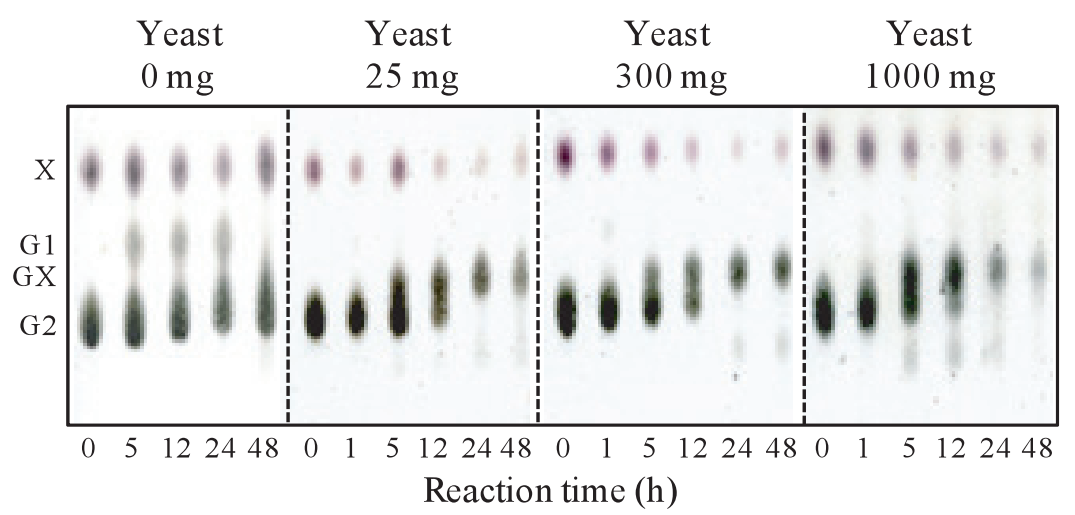

(b)

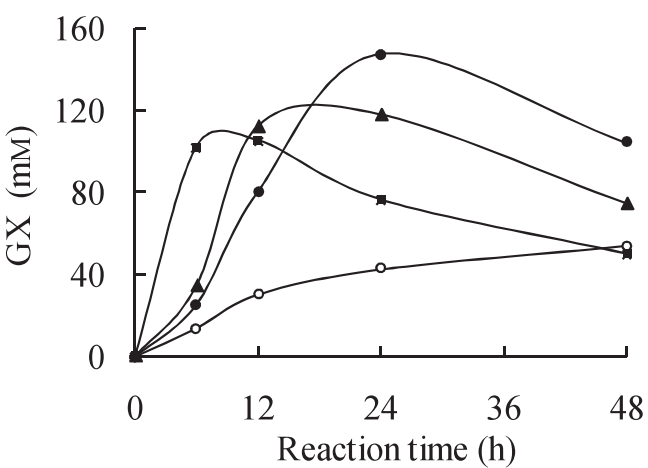

Fig. 3. Effect of adding various amounts of dry yeast on GX production.

Twenty-five $\mathrm{mg}, 300 \mathrm{mg}$, or 1,000 mg of dry yeast were suspended in $10 \mathrm{~mL}$ of standard mixture solution to synthesize GX using $500 \mathrm{mg}$ of acetone-treated mycelia $\left(4.0 \mathrm{U}\right.$ ) at $30^{\circ} \mathrm{C}$ with continuous shaking. (a) TLC showing the pattern of GX production. TLC was performed on a Silica Gel 60 A plate (Whatman plc, Kent, UK) with 75\% acetonitrile solution at room temperature, and sugar spots were detected by the sulfuric acidbaking method. ${ }^{14)} \mathrm{X}$, xylose; G1, glucose; G2, cellobiose; GX, glucosylxylose. (b) Quantitative determination of GX. The analytical method used was the same as that described in Fig. 2. Symbols indicate the amount of dry yeast added: $\bigcirc, 0 \mathrm{mg} ; \mathbf{O}, 25 \mathrm{mg} ; \boldsymbol{\Delta}, 300 \mathrm{mg}$; $\mathbf{\square}, 1,000 \mathrm{mg}$.

GX that was used as a standard contained crystalline water, the concentration of GX was calculated from its total carbon content in standard solution based on the formula $\mathrm{C}_{5} \mathrm{H}_{10} \mathrm{O}_{5}$. The total carbon content was analyzed using a Total Organic Carbon Analyzer TOC-VCSH (Shimadzu Corporation, Kyoto, Japan). As an enzymatic reaction without yeast, $500 \mathrm{mg}$ of acetone-treated mycelia $(4.0 \mathrm{U})$ were suspended in $10 \mathrm{~mL}$ of $50 \mathrm{~mm}$ Tris- $\mathrm{HCl}$ buffer ( $\mathrm{pH} 7.5$ ) containing $350 \mathrm{mM}$ cellobiose (saturated concentration), $350 \mathrm{mM}$ xylose (equimolar concentration to cellobiose), and $2 \mathrm{mM} \mathrm{K}-\mathrm{Na}$ phosphate buffer ( $\mathrm{pH} 7.5$ ). On the other hand, as an additional condition, $300 \mathrm{mg}$ of dry bakery yeast (Oriental Yeast Co., Ltd., Tokyo, Japan) was suspended in the standard reaction mixture to improve the yield of GX. These suspensions were incubated at $30^{\circ} \mathrm{C}$ with continuous shaking, and small aliquots of the reaction mixture were sampled at regular time intervals.

While cellobiose remained after $24 \mathrm{~h}$ in the conditions without yeast, almost all of the cellobiose had been consumed after $24 \mathrm{~h}$ in the conditions with yeast (Fig. 2). This indicated that the addition of dry yeast was effective at increasing GX production. Thus, the optimum amount of dry yeast was investigated. When $1,000 \mathrm{mg}$ of dry yeast was added to the reaction mixture, the GX spot was clearer after 5 hours' reaction compared to those observed after the addition of $25 \mathrm{mg}$ or $300 \mathrm{mg}$ dry yeast (Fig. 3(a)), and the concentration of GX reached $100 \mathrm{~mm}$ (Fig. 3(b)). However, the concentration of GX produced by the enzyme reaction gradually fell to the same level as was produced under the standard conditions after $48 \mathrm{~h}$. On the other hand, the highest concentration of GX (150 mM) was observed after $24 \mathrm{~h}$ under the $25 \mathrm{mg}$ dry yeast conditions. In these conditions, $42 \%$ of cellobiose was converted to GX, which was 3.5-times higher than that produced under the conditions without yeast after $24 \mathrm{~h}$. A decrease in the GX concentration was observed in all conditions although the rate of its decline differed. It was suggested that the yeast consumed not only glucose but also GX. These results indicate that choosing an appropriate amount of dry yeast and reaction time is important for efficient GX production.

In conclusion, GX production using a powdered CBPase- yeast combined system is simple and convenient. In a tentative analysis by our collaborators, GX stimulated the growth of lactic acid bacteria. Therefore, this process can be used to produce high-value materials from biomass.

\section{ACKNOWLEDGMENTS}

This work was supported by a grant from the Research and Development Program for New Bio-Industry Institute of the Bio-oriented Technology Research Advancement Institution and a Grant-in-Aid for the Global COE Program from the Ministry of Education, Culture, Sports, Science, and Technology.

\section{REFERENCES}

1 ) C.J. Sih and R.H. McBee: A cellobiose phosphorylase in Clostridium thermocellum. Proc. Mont. Acad. Sci., 15, 21-22 (1955).

2 ) M. Kitaoka, T. Sasaki and H. Taniguchi: Synthetic reaction of Cellvibrio gilvus cellobiose phosphorylase. J. Biochem., 112, 40-44 (1992).

3 ) S. Makishima, K. Nozaki, M. Mizuno, E. Netsu, K. Shinji, T. Shibayama, T. Kanda and Y. Amano: Recovery of soluble sugars from waste medium for Enokitake (Flammulina velutipes) mushroom cultivation with hydrothermal reaction and enzyme digestion. J. Appl. Glycosci., 53, 261-266 (2006).

4 ) T. Sasaki, T. Tanaka, S. Nakagawa and K. Kainuma: Purification and properties of Cellvibrio gilvus cellobiose phosphorylase. Biochem. J., 209, 803-807 (1983).

5 ) T. Christensen, H. Woeldike, E. Boel, S.B. Mortensen, K. Hjortshoej, L. Thim and M.T. Hansen: High level expression of recombinant genes in Aspergillus oryzae. Nat. Biotechnol., 6, 1419-1422 (1988).

6 ) Y. Hata, K. Tsuchiya, K. Kitamoto, K. Gomi, C. Kumagai, G. Tamura and S. Hara: Nucleotide sequence and expression of the glucoamylase-encoding gene ( $\mathrm{glaA}$ ) from Aspergillus oryzae. Gene, 108, 145-50 (1991).

7 ) K. Tsuchiya, S. Tada, K. Gomi, K. Kitamoto, C. Kumagai, Y. Jigami and G. Tamura: High level expression of the synthetic human lysozyme gene in Aspergillus oryzae. Appl. Microbiol. Biotechnol., 38, 109-114 (1992).

8 ) Y. Mabashi, T. Kimura, J. Maruyama, M. Arioka and K. Kitamoto: Development of a versatile expression plasmid construction system for Aspergillus oryzae and its application to visualization of mitochondria. Biosci. Biotechnol. Biochem., 70, 1882-1889 (2006).

9 ) S. Tada, Y. Iimura, K. Gomi, K. Takahashi, S. Hara and K. Yoshizawa: Cloning and nucleotide sequence of the genomic Taka-amylase A gene of Aspergillus oryzae. Agric. Biol. Chem., 53, 593-599 (1989). 
10) T. Kubodera, N. Yamashita and A. Nishimura: Pyrithiamine resistance gene ( $p t r A$ ) of Aspergillus oryzae: cloning, characterization and application as a dominant selectable marker for transformation. Biosci. Biotechnol. Biochem., 64, 1416-1421 (2000).

11) K. Gomi, Y. Iimura and S. Hara: Integrative transformation of Aspergillus oryzae with a plasmid containing the Aspergillus nidulans argB gene. Agric. Biol. Chem., 51, 2549-2555 (1987).

12) M. Kitaoka, H. Taniguchi and T. Sasaki: Production of glucosyl- xylose using Cellvibrio gilvus cells and its properties. Appl. Microbiol. Biotechnol., 34, 178-182 (1990).

13) G. Michal: D-Glucose 1-phosphate. in Methods of Enzymatic Analysis, H.U. Bergmeyer, ed., 2nd Ed., Vol. 4, Academic Press, New York, pp. 185-191 (1974).

14) G.W. Hay, B.A. Lewis and F. Smith: Thin-film chromatography in the study of carbohydrates. J. Chromatogr., 11, 479-486 (1963). 